\title{
The Utilization of Thiocyanate by a Heterotrophic Bacterium
}

\author{
By D. A. STAFFORD AND A. G. CALLELY \\ Microbiology Department, University College, Cathays Park, \\ Cardiff, CFI $3 N R$
}

(Accepted for publication 8 October 1968)

SUMMARY

A heterotrophic bacterium has been isolated which can use thiocyanate as its sole source of cellular nitrogen and also sulphur; ammonium ions inhibit the utilization of thiocyanate. It can utilize both phenol and thiocyanate simultaneously; it is a pseudomonad and is most similar to Pseudomonas stutzeri.

\section{INTRODUCTION}

The biodegradation of the thiocyanate ion, especially in biological effluent-treatment systems, is usually considered to be due to the action of autotrophs as, for example, the Thiobacillus described by Happold, Johnstone, Rogers \& Youatt (I954). It occurred to us that there might well be organisms growing heterotrophically which were capable of using thiocyanate as their source of cellular nitrogen and also, perhaps, sulphur. This paper reports the isolation of such an organism.

\section{METHODS}

Chemicals. All chemicals were either of AnalaR or the purest commercial grade obtainable from British Drug Houses Ltd., Poole, Dorset.

Media. The mineral-salts medium contained (g./l. distilled water): $\mathrm{KH}_{2} \mathrm{PO}_{4}$, I ; $\mathrm{K}_{2} \mathrm{HPO}_{4}, \mathrm{I} ; \mathrm{MgSO}_{4} .7 \mathrm{H}_{2} \mathrm{O}, 0.2 ; \mathrm{CaCl}_{2}, 0.02$; and $0 . \mathrm{I} \mathrm{ml.} 60 \%$ (w/v) $\mathrm{FeCl}_{3} .6 \mathrm{H}_{2} \mathrm{O}$. 'Sulphate-free' media contained $0.2 \mathrm{~g} . \mathrm{MgCl}_{2}$ instead of $\mathrm{MgSO}_{4}$. The solution was filtered and the filtrate adjusted to between $\mathrm{pH} 7.0$ and 7.4 with $\mathrm{NaOH}$; it was then sterilized at approx. $10^{5} \mathrm{~N} / \mathrm{m}^{2}$ for $15 \mathrm{~min}$. Disodium succinate (final concn. $25 \mathrm{~mm}$ ) or phenol (final concn. $5 \mathrm{mM}$ ) were added as the carbon and energy source. For the source of nitrogen either $\mathrm{KSCN}$ (final concn. $4 \mathrm{mM}$ ) or $\left(\mathrm{NH}_{4}\right)_{2} \mathrm{SO}_{4}$ (final concn. $2 \mathrm{~mm}$ ) was used. All supplements were added aseptically after sterilization as above.

Thiobacillus-enrichment medium was medium no. 2 described by Parker \& Prisk (1953).

Media were solidified when necessary by the addition of $3 \%(w / v)$ washed Ionagar no. 2 (Oxoid).

Isolation and maintenance of the organism. The organism was isolated by plating out, on to solid Thiobacillus-enrichment medium, a sample taken from an activatedsludge tank treating primarily $\mathrm{NH}_{4} \mathrm{SCN}$. After overnight incubation at $30^{\circ}$ eight different colonial types were observed, which were individually transferred on succinate + thiocyanate + mineral-salts agar. Only one of these eight organisms had grown 
well after overnight incubation at $30^{\circ}$. An individual colony from this plate was used to inoculate a liquid succinate + thiocyanate + mineral-salts medium and the culture was shaken at $30^{\circ}$ overnight. Good growth resulted which was coupled with the disappearance of thiocyanate; the culture obtained was morphologically homogeneous.

The organism was maintained by subculturing on to both nutrient-agar and succinate + thiocyanate + mineral-salts agar. Growth studies were always performed in $500 \mathrm{ml}$. Erlenmeyer flasks containing $100 \mathrm{ml}$. medium; these were shaken at $150 \mathrm{rev} . /$ min. in an orbital incubator at $30^{\circ}$.

Analytical methods. All turbidimetric or spectrophotometric assays were done with a Unicam SP. 600 with cuvettes with a I cm. light-path.

The extinction, at $450 \mathrm{~m} \mu$, of undiluted samples of culture medium was used as a measurement of growth.

Thiocyanate was estimated by adding to a $0.5 \mathrm{ml}$. sample, $0.5 \mathrm{ml} .5 \mathrm{~N}$-nitric acid, $9.5 \mathrm{ml}$. distilled water and $0.5 \mathrm{ml}$. $10 \%(\mathrm{w} / \mathrm{v}$ ) iron (III) nitrate; in the corresponding control the iron(III) nitrate was replaced by an equal volume of water. The extinction of the final colour was read at $4 \mathrm{ro} \mathrm{m} \mu$.

Phenol was estimated by the 4 -aminophenazone method of Shaw (I95I).

Sulphate was determined by the barium chloranilate method of Bertolacini \& Barney (1957).

Nessler reagent was used to assay ammonia.

Diagnostic tests. The tests used to identify the organism were the same as those described by Stanier, Palleroni \& Doudoroff (1966), except that the number of flagella was determined from electron-micrographs of the whole organism.

\section{RESULTS}

\section{Characters of the organism}

The isolated organism was a Gram-negative unicellular straight rod (measuring I. $0 \mu \times 0.8 \mu$ ), motile by means of one to eight flagella at one pole of the organism. It gave a very rapid positive result in the oxidase test and utilized denitrification as an anaerobic respiratory mechanism. Besides succinate and phenol (catechol is not cleaved by the meta-mechanism) it grew with either glucose, maltose or glycollate as the sole source of carbon and energy; starch was hydrolysed, gelatin was not. No growth took place on nutrient agar at $4^{\circ}$ over a period of ten days; growth was good at $4 \mathrm{I}^{\circ}$.

Pigment was not produced under any conditions of growth tried, even when cultured on both of the complex media (A and B) designed by King, Ward \& Raney (1954) to detect the two commonestitypes of pigments produced by pseudomonads. On medium $B$ it exhibited the unusual colony structure which has been used to distinguish Pseudomonas stutzeri (van Niel \& Allen, 1952): both the rough, wrinkled, dry and coherent form together with the smooth colonial variants were readily observed, from either a single rough or a single smooth parent colony.

\section{Growth studies with thiocyanate}

In either a phenol or succinate + mineral-salts medium the organism used thiocyanate or ammonium ion as sole source of cellular nitrogen. Growth of the organism and disappearance during growth of both phenol and thiocyanate is shown in Fig. I; 


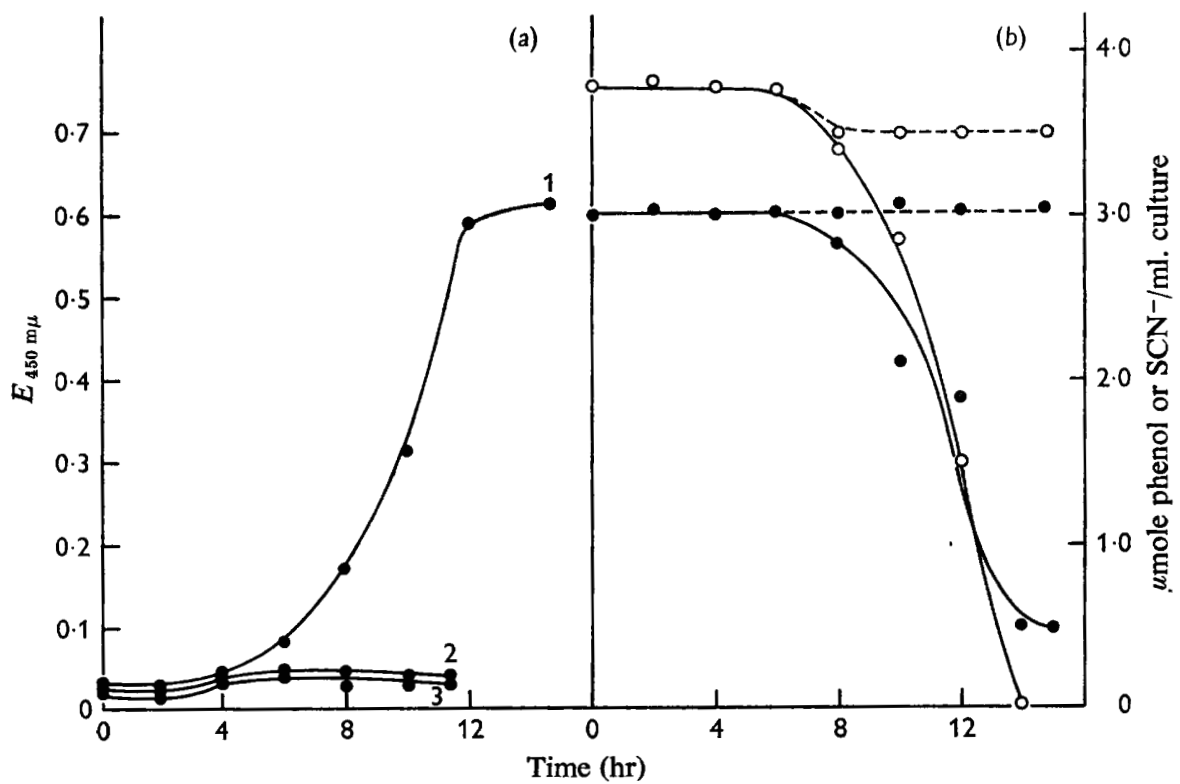

Fig. I. (a) Growth of the organism at $30^{\circ}$ in a shaken ammonium ion-free mineral-salts medium supplemented with (I) phenol as the sole source of carbon and energy, and thiocyanate as the sole source of nitrogen; (2) phenol only; (3) thiocyanate only. (b) Disappearance of phenol and thiocyanate during growth. - - -, phenol concentration in medium I $(a)$; $-\mathrm{O}_{-}-$, phenol concentration in medium $2,(a)$; - - , thiocyanate concentration in medium I $(a)$; - - - , thiocyanate concentration in medium $3(a)$.

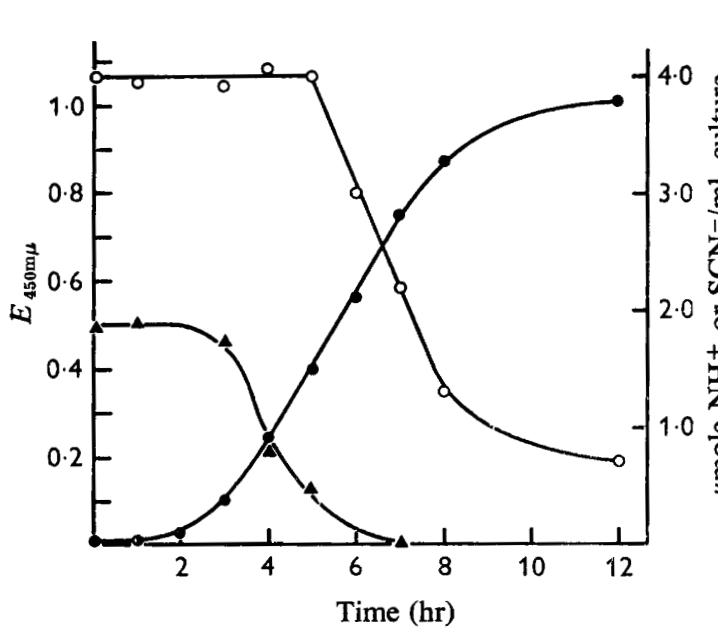

Fig. 2

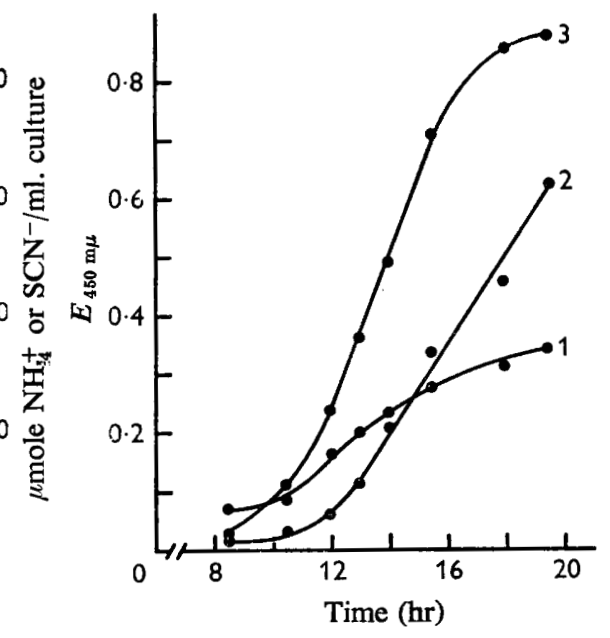

Fig. 3

Fig. 2. Disappearance of $\mathrm{NH}_{4}^{+}$and $\mathrm{SCN}$ - during growth of the organism at $30^{\circ}$ in a shaken succinate/thiocyanate/ammonium-salt/mineral-salts medium. $\bullet$, growth; $O$, thiocyanate concentration; $\boldsymbol{\Delta}$ ammonium ion concentration. For experimental details see text.

Fig. 3. Growth of the organism at $30^{\circ}$ in a shaken 'sulphate-free' medium with succinate as the sole source of carbon and energy, supplemented with (I) $\mathrm{NH}_{4}^{+}$and $\mathrm{SCN}^{-}$as the only sources of added nitrogen and sulphur, (2) $\mathrm{SCN}^{-}$as the single source of nitrogen and sulphur, (3) $\mathrm{NH}_{4}^{+}, \mathrm{SCN}^{-}$, and $\mathrm{SO}_{4}^{\prime \prime}$ as the sources of nitrogen and sulphur. 
ammonium ions were detected in the culture filtrate towards the end of the growth cycle. At the usual concentration of the carbon and energy sources used, 3 mM-thiocyanate was sufficient for maximal growth. Whenever the carbon and energy source was exhausted in the presence of excess thiocyanate growth stopped abruptly and the concentration of thiocyanate ceased to decrease.

When thiocyanate and ammonium ions were present together in the growth medium thiocyanate degradation did not occur until the ammonium ions were nearly used up (Fig. 2). Addition of ammonium ions to a culture growing with thiocyanate inhibited the further utilization of this compound though this effect did not appear to be instantaneous.

No intra- or extra-cellular sulphur was produced, nor was sulphide detected, during growth with thiocyanate as the sole source of nitrogen. The sulphate concentration of the medium increased during growth with thiocyanate acting as the sole source of added sulphur as well as of nitrogen; when ammonium ions were added to such a medium growth was markedly inhibited (Fig. 3).

\section{DISCUSSION}

The organism described in this paper fits the definition of a pseudomonad given by Stanier et al. (1966) (its DNA base content has not been measured). Especially characteristic is the organism's rough and smooth colonial variation. This property has traditionally been used to identify such a pseudomonad as Pseudomonas stutzeri (for example, van Niel \& Allen, 1952), but our organism differs from the Stanier et al. (1966) description of Pseudomonas stutzeri in that it is not monotrichous and it contains a constitutive 'arginine dihydrolase'.

Another feature is the ability of our organism to metabolize thiocyanate, for thiocyanate degradation is usually considered to be due entirely to the activities of certain thiobacilli. One of the 'Thiobacillus' strains (no. $5 \mathrm{C}$ ) isolated by Hutchinson, Johnstone \& White (1965) was stated to be very similar to Pseudomonas stutzeri though no data on the similarity were given. Our organism, though growing readily in media suitable for non-exacting heterotrophs, has never been cultured autotrophically and, in our hands, has never utilized thiocyanate as a sole source of energy.

Thiocyanate was readily shown to be a sole source of nitrogen; it was not so straightforward to demonstrate that it could be the sole source of sulphur. Sulphate-free media are not easy to prepare because traces of sulphate were present in most of the chemicals used. Furthermore, since sulphate is produced during thiocyanate utilization some sulphate was always carried over with the inocula used in the growth experiments. The organism did grow, though after a much longer lag, as well in the 'sulphate-free' media as in media containing added sulphate.

The marked inhibition of growth in 'sulphate-free' media caused by the addition of ammonium ions could be due to their inhibition of thiocyanate utilization which would effectively cut the supply of sulphur. That ammonium ions do repress thiocyanate utilization suggests that they lie on the pathway of nitrogen assimilation from thiocyanate.

The ability of the organism to metabolize phenol and thiocyanate simultaneously makes it potentially very useful in the biological treatment of effluents containing such compounds. The removal of both these compounds in a one-stage process is not 
usually efficiently achieved, yet this organism grew in a medium containing $8 \mathrm{~mm}$ phenol +4 mM-thiocyanate, both of which disappeared during growth. A prior removal of ammonia from liquors to be treated by such organisms would, however, be necessary.

We are indebted to Mr W. Hodgkiss (Torry Research Station, Aberdeen) for taking electron micrographs of the organism and determining the number of flagella; also to Dr G. Hobbs (Torry Research Station) for helpful advice. We are grateful to the Science Research Council for a training grant to one of us (D.A.S.) and to the National Coal Board for additional financial assistance. The valuable technical assistance of $\mathrm{Mr} \mathrm{J}$. Rees is greatly appreciated.

\section{REFERENCES}

Bertolacini, R. J. \& BARNEY, J. E. (I957). Colourimetric determination of sulphate with barium chloranilate. Analyt. Chem. 29, 28I.

Happold, F. C., Johnstone, K. I., Rogers, H. J. \& YouatT, J. B. (1954). The isolation and characteristics of an organism oxidising thiocyanate. J. gen. Microbiol. ro, 261.

Hutchinson, M., Johnstone, K. I. \& White, D. (1965). The taxonomy of certain thiobacilli. J. gen. Microbiol. 4I, 357.

KING, E. O., WARD, M. K. \& RANEY, D. E. (1954). Two simple media for the demonstration of pyocyanin and fluorescein. J. Lab. clin. Med. 44, $30 \mathrm{I}$.

PARKer, C. D. \& PrIsK, J. (1953). The oxidation of inorganic compounds of sulphur by various sulphur bacteria. J. gen. Microbiol. 8, 344.

SHAw, J. A. (195I). Determination of phenols in aqueous wastes from coke plants. Analyt. Chem. 23, 1788.

Stanier, R. Y., Palleron, N. J. \& Doudoroff, M. (I966). The aerobic pseudomonads: a taxonomic study. J. gen. Microbiol. 43, 159.

van Niel, C. B. \& Allen, M. B. (1952). A note on Pseudomonas stutzeri. J. Bact. 64, 413. 